\title{
Modelo Hidrológico Híbrido para Previsão de Vazões na Bacia do Rio Piracicaba-MG
}

\author{
Eduardo Morgan Uliana $^{1}$ (D), Demetrius David da Silva ${ }^{2}$ (D), Michel Castro Moreira ${ }^{3}$ (D), \\ Donizete dos Reis Pereira $^{2}$ (D), Frederico Terra de Almeida ${ }^{1}$ \\ ${ }^{1}$ Instituto de Ciências Agrárias e Ambientais, Universidade Federal de Mato Grosso, Sinop, \\ MT, Brasil. \\ ${ }^{2}$ Departamento de Engenharia Agrícola, Universidade Federal de Viçosa, Viçosa, MG, Brasil. \\ ${ }^{3}$ Centro das Ciências Exatas e das Tecnologias, Universidade Federal do Oeste da Bahia, \\ Barreiras, BA, Brasil.
}

Recebido em: 1 de Agosto de 2017 - Aceito em: 14 de Janeiro de 2019

\begin{abstract}
Resumo
Os modelos hidrológicos conceituais e as Redes Neurais Artificiais (RNAs) podem ser associados, caracterizando uma conformação híbrida que represente, ao mesmo tempo, os processos conceituais e não lineares relacionados ao escoamento. O objetivo do trabalho foi avaliar a utilização das RNAs combinadas aos modelos hidrológicos conceituais IPH II e SAC-SMA, de forma a obter um modelo híbrido para estimativa de vazões dos cursos de água da bacia do rio Piracicaba-MG. Como dados de entrada das RNAs foram utilizadas as vazões estimadas com os modelos IPH II e SACSMA e como paradigma neural foi empregado o Perceptron de múltiplas camadas. Para o treinamento e a validação das RNAs foram utilizados dados de estações pluviométricas, fluviométricas e meteorológica localizadas na bacia hidrográfica do rio Piracicaba e no seu entorno. A fim de se verificar o desempenho dos modelos híbridos na estimativa das vazões da bacia do rio Piracicaba, as vazões estimadas por esses modelos foram comparadas com as vazões medidas nas estações fluviométricas utilizando-se o erro absoluto médio (MAE); a raiz do erro quadrático médio (RMSE); o viés; o índice de concordância de Willmott (d); e o índice de eficiência de Nash-Sutcliffe $\left(\mathrm{E}_{\mathrm{NS}}\right)$. A utilização das vazões preditas pelo modelo IPH II como dado de entrada das RNAs aumentou a acurácia das estimativas das vazões visto que o erro do modelo híbrido ficou menor. Já a associação das RNAs com o modelo SAC-SMA não proporcionou melhoria das estimativas quando comparada aos resultados advindos da aplicação isolada do referido modelo. Com base nos resultados obtidos pode-se concluir que a associação das RNAs com o modelo hidrológico IPH II, caracterizando uma conformação híbrida, permitiu melhorar as estimativas das vazões diárias na bacia do rio Piracicaba e que a qualidade das estimativas do modelo híbrido depende do modelo conceitual utilizado. Detectou-se, ainda, que os modelos híbridos tiveram melhor desempenho na estimativa das vazões associadas às maiores áreas de drenagem da bacia do rio Piracicaba.
\end{abstract}

Palavras-chave: inteligência artificial, modelo empírico, acurácia, modelagem hidrológica.

\section{Hybrid Hydrological Model for Water Flow Prediction in the Piracicaba River Basin-MG, Brazil}

\begin{abstract}
The association of conceptual hydrological models and artificial neural networks (ANNs) characterizes a hybrid conformation that represents simultaneously conceptual and non-linear processes related to water flow. This study aimed to evaluate the use of ANNs combined with the conceptual hydrological models IPH II and SAC-SMA to obtain a hybrid model for the estimation of watercourse flows in the Piracicaba River basin, located in the state of Minas Gerais - Brazil. The water flow rates estimated by IPH II and SAC-SMA models were used as input data for the ANN, and a multi-
\end{abstract}

Autor de correspondência: Eduardo Morgan Uliana, morganuliana@gmail.com. 
layered perceptron was employed as a neural paradigm. Data from pluviometric, fluviometric, and meteorological stations located in the studied basin and surrounding areas were used for the ANN training and validation. To verify the performance of the hybrid models in estimating water flow, the estimated flow rates were compared with those measured in the fluviometric stations using mean absolute error (MAE), root mean square error (RMSE), bias, Willmott's concordance index, and Nash-Sutcliffe efficiency index $\left(\mathrm{E}_{f}\right)$. The results showed that the use of IPH II model as input data for an ANN increased the accuracy of flow prediction as the hybrid model error decreased. Conversely, if compared to the results from its isolated application, when associated with the ANN, SAC-SMA-model did not improve water flow estimates. Lastly, the hybrid conformation using the IPH II hydrological model improved daily flow estimates of the Piracicaba River basin; therefore, the quality of estimates in a hybrid model depends on the conceptual model used. In addition, the hybrid models had better performance when estimating water flows in larger drainage areas within the Piracicaba River basin.

\section{Introdução}

Em geral, os modelos hidrológicos podem ser classificados como conceituais, empíricos, de base física e híbridos. O modelo conceitual considera a bacia hidrográfica como uma série de compartimentos interconectados que representam os elementos físicos da bacia. O armazenamento e o escoamento da água nesse tipo de modelo são quantificados por meio de equações semi-empíricas, cujos parâmetros podem ser obtidos a partir de dados de campo, mas também por meio de calibração. Já o modelo empírico é constituído de equações que estabelecem uma relação entre os dados de entrada e saída de um sistema hídrico, sem levar em consideração os processos físicos intervenientes na variável a ser estimada. Diferente dos anteriores, o modelo de base física baseia-se na solução de equações diferenciais do sistema físico e os seus parâmetros são aqueles que mais se aproximam da física do sistema. Por fim, os modelos híbridos são constituídos da combinação de modelos conceituais, empíricos e de base física, com o objetivo de estimar a variável de interesse (Devi et al., 2015; Pechlivannidis et al., 2011; Tucci, 2005).

Dentre os modelos empíricos, as Redes Neurais Artificiais (RNAs) apresentam resultados promissores para a estimativa das vazões de cursos de água, como demonstrado por Aichouri et al. (2015), Elsafi (2014), Gomes et al. (2010), Meng et al. (2015), Oliveira et al. (2013), Sattari et al. (2012), Setiono (2015) e Sousa e Sousa (2010).

Existe um grande número de modelos hidrológicos conceituais chuva-vazão, com características únicas e aplicações específicas (Devi et al., 2015). Dentre esses modelos destacam-se o IPH II (Tucci, 2005) e o Sacramento - Soil Moisture Accounting (SAC-SMA) (Burnash, 1995).

O modelo IPH II foi desenvolvido no Instituto de Pesquisas Hidráulicas da Universidade Federal do Rio Grande do Sul (UFRGS) com objetivo de ser utilizado para projetos de engenharia em bacias hidrográficas. Já o modelo SAC-SMA foi desenvolvido nos Estados Unidos para previsão de cheias no rio Sacramento (Califórnia).

As RNAs são consideradas como um método substituto aos modelos conceituais chuva-vazão, mas esses mo-
, hydrological modeling.

delos podem ser associados, caracterizando uma conformação híbrida, como exposto por Nilsson et al. (2006). Esses autores utilizaram as RNAs e o modelo Hydrologiska Byråns Vattenbalansavdelning (HBV) para estimar o escoamento de duas bacias hidrográficas Norueguesas e concluíram que acurácia das estimativas melhorou com a combinação dos dois métodos.

Noori e Kalin (2016) trabalharam com a associação do modelo hidrológico SWAT com as RNAs para estimativa de vazões diárias em 29 bacias localizadas próximas à cidade de Atlanta, Estados Unidos. Esses autores utilizaram as vazões diárias preditas com o modelo SWAT como dado de entrada das RNAs e concluíram que o acoplamento dos modelos melhorou a estimativa das vazões. Ainda segundo os autores, a associação das RNAs com modelos conceituais pode ajudar a superar as limitações de cada modelo, resultando em um modelo híbrido com maior acurácia para a previsão de vazões.

Contudo, ainda é preciso evoluir nesse tipo de análise com a avaliação desta conformação híbrida com outros modelos conceituais e aplicados, sobretudo, em bacias tropicais.

O objetivo do trabalho foi avaliar a utilização das RNAs combinadas aos modelos hidrológicos conceituais IPH II e SAC-SMA, de forma a obter um modelo híbrido robusto para estimativa de vazões dos cursos de água da bacia do rio Piracicaba-MG.

\section{Material e Métodos}

\section{1. Área de estudo e base de dados}

O estudo foi conduzido na bacia do rio Piracicaba, que possui 5.304,0 $\mathrm{km}^{2}$ de área e localiza-se no Estado de Minas Gerais (Fig. 1).

Para a calibração e validação dos modelos conceituais IPH II e SAC-SMA bem como para o treinamento e a validação das redes neurais artificiais (RNAs) foram utilizados dados de estações pluviométricas, fluviométricas e meteorológica localizadas na bacia hidrográfica e em seu entorno (Tabela 1 e Fig. 1).

Foram utilizados no estudo dados diários de vazões correspondentes aos períodos de 01/09/1990 a 31/12/1993, $01 / 07 / 2002$ a $31 / 12 / 2006$ e $01 / 09 / 1990$ a $31 / 12 / 1992$, 


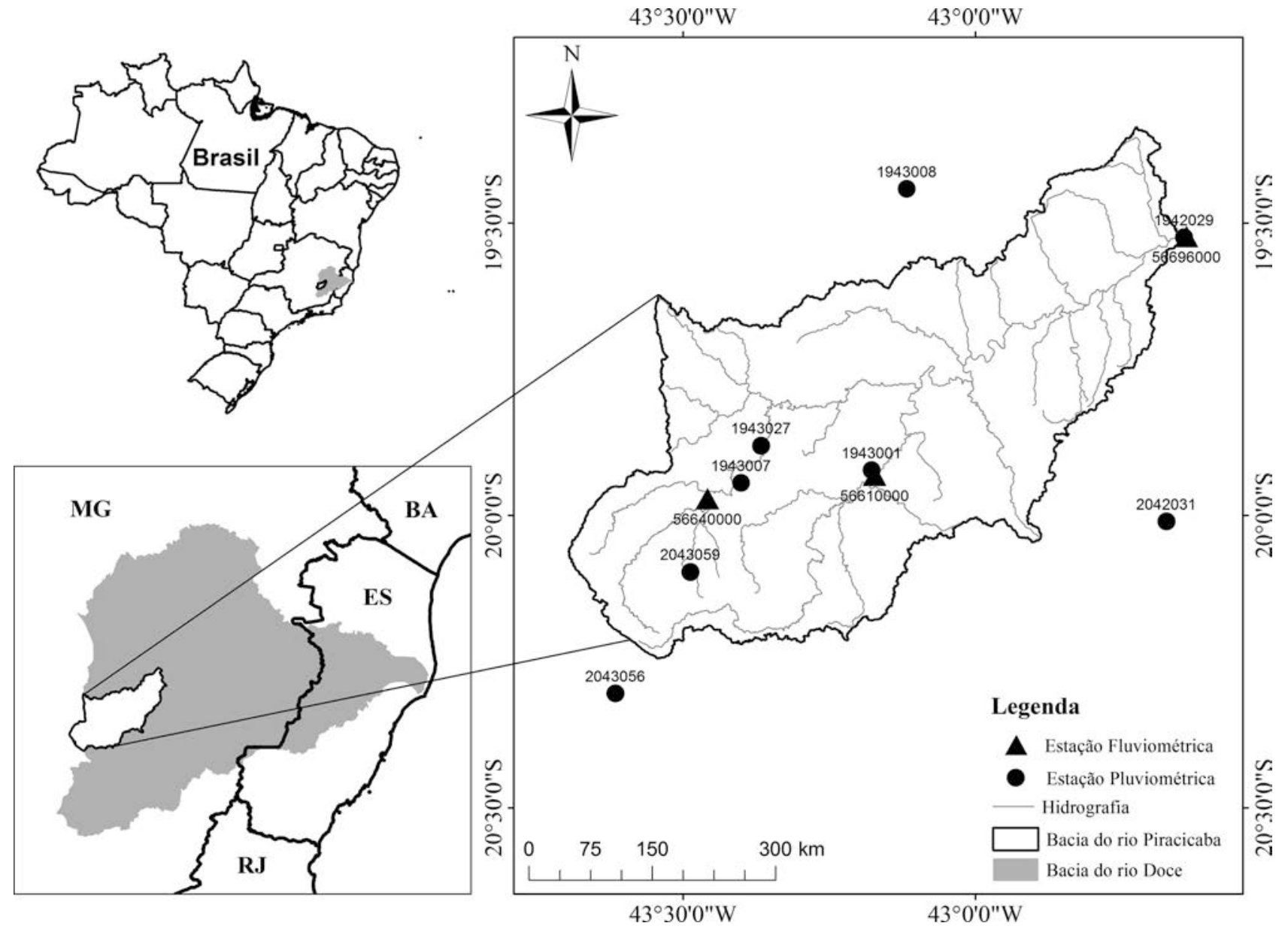

Figura 1 - Bacia hidrográfica do rio Piracicaba, com destaque para a localização das estações pluviométricas e fluviométricas utilizadas no estudo.

Tabela 1 - Informações sobre as estações pluviométricas, fluviométricas e meteorológica utilizadas no estudo.

\begin{tabular}{|c|c|c|c|c|c|c|}
\hline Código & Nome & Estação & Latitude $\left({ }^{\circ}\right)$ & Longitude $\left({ }^{\circ}\right)$ & Altitude (m) & $\operatorname{Ad}\left(\mathrm{km}^{2}\right)$ \\
\hline 01942029 & Mário de Carvalho & $\mathrm{P}$ & $-19,525$ & $-42,644$ & 232 & - \\
\hline 01943008 & Santa Maria do Itabira & $\mathrm{P}$ & $-19,442$ & $-43,118$ & 538 & - \\
\hline 01943027 & Usina Peti & $\mathrm{P}$ & $-19,881$ & $-43,367$ & 1.110 & - \\
\hline 02042031 & Fazenda Cach. D'Antas & $\mathrm{P}$ & $-20,011$ & $-42,674$ & 280 & - \\
\hline 02043059 & Colégio Caraça & $P$ & $-20,097$ & $-43,488$ & 1.300 & - \\
\hline 02043056 & Fazenda Água Limpa & $\mathrm{P}$ & $-20,305$ & $-43,616$ & 965 & - \\
\hline 01943007 & Santa Bárbara & $\mathrm{P}$ & $-19,945$ & $-43,401$ & 748 & - \\
\hline 01943001 & Rio Piracicaba & $\mathrm{P}$ & $-19,923$ & $-43,178$ & 623 & - \\
\hline 56640000 & Carrapato & $\mathrm{F}$ & $-19,972$ & $-43,459$ & 755 & 427,5 \\
\hline 56610000 & Rio Piracicaba & $\mathrm{F}$ & $-19,932$ & $-43,173$ & 748 & $1.164,2$ \\
\hline 56696000 & Mário de Carvalho & $\mathrm{F}$ & $-19,524$ & $-42,640$ & 232 & $5.304,0$ \\
\hline 2042024 & Viçosa & M & $-20,766$ & $-42,866$ & 712 & - \\
\hline
\end{tabular}

Ad: área de drenagem; P: estação pluviométrica; F: estação fluviométrica; M: estação meteorológica.

registrados, respectivamente, nas estações fluviométricas 56696000 (Mário de Carvalho), 56610000 (Rio Piracicaba) e 56640000 (Carrapato) assim como dados pluviométricos e climáticos (Tabela 1). Esses períodos foram sele- cionados por não apresentarem falhas nos dados hidrometeorológicos das estações listadas na Tabela 1. A consideração desses períodos teve maior importância para a calibração e validação dos modelos conceituais IPH II e 
SAC-SMA, uma vez que precisava-se de séries contínuas e sem falhas para execução dessas etapas.

Com a finalidade de obter um modelo híbrido mais acurado, oriundo da associação de modelos hidrológicos conceituais e Redes Neurais Artificiais (RNAs) foram utilizadas as vazões estimadas com os modelos IPH II e SAC-SMA como dados de entrada das RNAs.

Os modelos IPH II e SAC-SMA requerem como variáveis de entrada dados de precipitação e evapotranspiração de referência $\left(\mathrm{ET}_{0}\right)$. Com vistas à calibração automática e validação desses modelos hidrológicos, para fins de estimativa das vazões diárias na bacia do rio Piracicaba, foram utilizados dados de estações pluviométricas, fluviométricas e meteorológica apresentadas na Tabela 1. O período de dados utilizado foi o mesmo selecionado para desenvolvimento das RNAs.

A precipitação média na área de drenagem de cada sub-bacia foi obtida pelo método de Thiessen, descrito por Macêdo et al. (2013), e a evapotranspiração de referência $\left(\mathrm{ET}_{0}\right)$ diária foi calculada pelo método de Hargreaves e Samani, conforme Borges Júnior et al. (2012).

Para calibração automática dos modelos hidrológicos IPH II e SAC-SMA foi utilizado o algoritmo Shuffled Complex Evolution (SCE-UA), desenvolvido por Duan et al. (1992). A função objetivo escolhida para a calibração foi o coeficiente de Nash-Sutcliffe, conforme descrito por Pereira et al. (2014). Para execução dessa etapa e para estimativa das vazões com esses modelos foram utilizados o software WIN-IPH2 (Bravo et al., 2006) e um algoritmo, implementado em linguagem de programação R, denominado hydromad (Andrews et al., 2011).

Com as vazões estimadas pelos modelos IPH II $\left(\mathrm{Q}_{\mathrm{IPH}}\right)$ e SAC-SMA $\left(\mathrm{Q}_{\mathrm{Sac}}\right)$ foram propostas as entradas das RNAs (Tabela 2). Esses dados de entrada permitiram avaliar a associação entre os modelos hidrológicos e as RNAs para estimativa da vazão diária $\left(Q_{t}\right)$, como sugerido por Nilsson et al. (2006) e Noori e Kalin (2016).

\subsection{Arquitetura e treinamento das redes}

No desenvolvimento das redes foram realizadas a coleta e seleção dos dados de entrada e saída; a definição da arquitetura da rede e o treinamento e validação das redes desenvolvidas.

Os dados de entrada foram organizados aleatoriamente e normalizados, utilizando a equação

$$
\mathrm{pn}=\frac{2(\mathrm{p}-\min p)}{(\operatorname{maxp}-\min p)}-1
$$

em que pn é o valor normalizado (variando entre -1 e 1), p é o valor da variável, e minp e maxp são, respectivamente, o menor e o maior valor da variável na série em estudo.

Segundo Silva et al. (2010), a normalização garante que cada dado de entrada receba a mesma atenção durante o treinamento da RNA, implicando melhor eficiência
Tabela 2 - Variáveis de entrada utilizadas para o desenvolvimento das redes neurais artificiais (RNAs), considerando as vazões estimadas com os modelos conceituais SAC-SMA e IPH II.

\begin{tabular}{cc}
\hline Entrada & Entrada \\
\hline $\mathrm{Q}_{\mathrm{Sac}}$ & $\mathrm{Q}_{\mathrm{IPH}}$ \\
$\mathrm{Q}_{\mathrm{Sac}} \mathrm{t}-1$ & $\mathrm{Q}_{\mathrm{IPH} \mathrm{t}-1}$ \\
$\mathrm{Q}_{\mathrm{Sac}} \mathrm{t}-2$ & $\mathrm{Q}_{\mathrm{IPH} \mathrm{t}-2}$ \\
$\mathrm{P}_{\mathrm{t}} ; \mathrm{Q}_{\mathrm{Sac}}$ & $\mathrm{P}_{\mathrm{t}} ; \mathrm{Q}_{\mathrm{IPH}}$ \\
$\mathrm{Q}_{\mathrm{t}-1} ; \mathrm{Q}_{\mathrm{Sac}}$ & $\mathrm{Q}_{\mathrm{t}-1} ; \mathrm{Q}_{\mathrm{IPH}}$ \\
$\mathrm{Q}_{\mathrm{mt}-2} ; \mathrm{Q}_{\mathrm{Sac}}$ & $\mathrm{Q}_{\mathrm{mt}-2} ; \mathrm{Q}_{\mathrm{IPH}}$ \\
$\mathrm{Q}_{\mathrm{mt}-3} ; \mathrm{Q}_{\mathrm{Sac}}$ & $\mathrm{Q}_{\mathrm{mt}-3} ; \mathrm{Q}_{\mathrm{IPH}}$ \\
$\mathrm{Q}_{\mathrm{mt}-4} ; \mathrm{Q}_{\mathrm{Sac}}$ & $\mathrm{Q}_{\mathrm{mt}-4} ; \mathrm{Q}_{\mathrm{IPH}}$ \\
$\mathrm{P}_{\mathrm{t}} ; \mathrm{E}_{\mathrm{t}} ; \mathrm{Q}_{\mathrm{Sac}}$ & $\mathrm{P}_{\mathrm{t}} ; \mathrm{E}_{\mathrm{t}} ; \mathrm{Q}_{\mathrm{IPH}}$ \\
\hline
\end{tabular}

$\mathrm{Q}_{\mathrm{Sac}}$ é a vazão diária estimada com o modelo SAC-SMA $\left(\mathrm{m}^{3} \mathrm{~s}^{-1}\right) ; \mathrm{Q}_{\mathrm{Sac}} \mathrm{t}-\mathrm{n}$ é a vazão diária estimada com o modelo SAC-SMA defasada em n dias $\left(\mathrm{m}^{3} \mathrm{~s}^{-1}\right) ; \mathrm{Q}_{\mathrm{IPH}}$ é a vazão diária estimada com o modelo IPH II $\left(\mathrm{m}^{3} \mathrm{~s}^{-1}\right)$; $\mathrm{Q}_{\text {IPH } \mathrm{t} \text {-n }}$ é a vazão diária estimada com o modelo IPH II defasada em n dias $\left(\mathrm{m}^{3} \mathrm{~s}^{-1}\right) ; \mathrm{Q}_{\mathrm{t}-\mathrm{n}}$ é a vazão diária defasada em $\mathrm{n}(1,2,3, \ldots, \mathrm{n})$ dias $\left(\mathrm{m}^{3} \mathrm{~s}^{-1}\right)$; $\mathrm{P}_{\mathrm{t}}$ é a precipitação da bacia no tempo $\mathrm{t}(\mathrm{mm})$ obtida pelo método de Thiessen (Macêdo et al., 2013); $\mathrm{E}_{\mathrm{t}}$ é a evapotranspiração de referência no tempo $\mathrm{t}(\mathrm{mm})$ obtida pelo método de Hargreaves e Samani (Borges Júnior et al., 2012); e $\mathrm{Q}_{\mathrm{m}_{\mathrm{n}}}$ é a vazão média de $\mathrm{n}(2,3, \ldots, \mathrm{n})$ dias anteriores $\left(\mathrm{m}^{3} \mathrm{~s}^{-1}\right)$.

numérica diante das operações matemáticas realizadas pela rede.

Após a aleatorização e normalização os dados foram separados em duas categorias: dados de treinamento, que foram utilizados para treinamento da rede; e dados de validação, que foram utilizados para verificar o desempenho da rede. Neste estudo, $85 \%$ dos dados da série foram utilizados para treinamento e $15 \%$ para validação.

A unidade de processamento das RNAs é o neurônio matemático (Fig. 2), sendo seu funcionamento definido na Eq. (2).

$$
y_{j}=F\left(\sum_{i=1}^{n} W_{i j} X_{i}+b_{j}\right)
$$

em que $y_{j}$ é o valor da resposta do neurônio (valores das variáveis de saída); $F$, a função de ativação ou transferência; $W_{i j}$, os pesos sinápticos; $X_{i}$, os valores das variáveis de entrada, que são processados no neurônio; e $b_{j}$ (bias), o valor de compensação do neurônio matemático.

Como paradigma neural foi empregado o Perceptron de múltiplas camadas, o qual, segundo Araújo et al. (2015), é muito utilizado para a modelagem de fenômenos em engenharia. As RNAs foram do tipo retroalimentadas, possuindo uma camada de entrada, duas camadas intermediárias e uma camada de saída.

Como funções de transferência foram adotadas a tangente hiperbólica nas camadas intermediárias e a função tangente na camada de saída das RNAs. Foi priorizada a função tangente hiperbólica nas camadas intermediárias, 


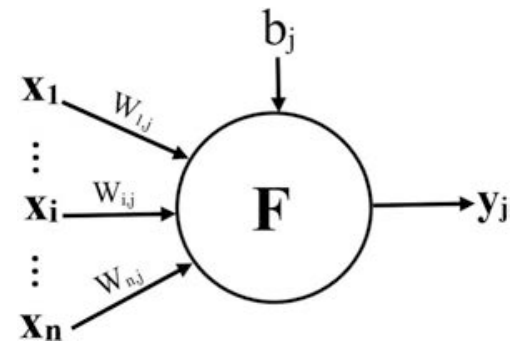

Figura 2 - Esquema de um neurônio artificial. Fonte: Adaptado de Govindaraju (2000).

em decorrência da sua característica de antissimetria melhorar o processo de convergência da rede durante o treinamento, como constatado por Silva et al. (2010).

$\mathrm{O}$ número de neurônios em cada camada intermediária foi definido empiricamente, durante o processo de treinamento da rede, de forma a obter o menor erro de estimativa das vazões diárias. Para evitar a memorização da rede (overfitting), caracterizada pela redução de sua capacidade de generalização, o número máximo de neurônios artificiais em cada camada intermediária foi limitado a 10. Esse número foi definido com base nos valores estabelecidos por Noori e Kalin (2016), ao utilizarem o modelo para estimativa de vazões.

No treinamento da rede foi utilizado o algoritmo backpropagation (Silva et al., 2010), conhecido também como algoritmo de retropropagação do erro, incorporado ao algoritmo de otimização de Levenberg-Marquardt, como proposto por Asadi et al. (2013), de forma a minimizar o esforço computacional e o problema de convergência muito lenta, decorrente da utilização de forma isolada do algoritmo backpropagation.

Durante o treinamento, foi estabelecido um limite máximo de épocas (epochs) como critério adicional de parada do algoritmo, quando a precisão especificada se tornou inalcançável.

A quantidade de épocas é definida como o número de tentativas de ajuste dos pesos $\left(\mathrm{w}_{\mathrm{ij}}\right)$ e bias $\left(\mathrm{b}_{\mathrm{j}}\right)$ (Eq. (2)) da RNA, de forma a garantir acurácia nas estimativas da variável de saída (Govindaraju, 2000).

\subsection{Avaliação do desempenho dos modelos}

A fim de se verificar o desempenho dos modelos híbridos na estimativa das vazões da bacia do rio Piracicaba, as vazões estimadas por esses modelos foram comparadas com as vazões medidas nas estações fluviométricas utilizando-se as seguintes medidas estatísticas: erro absoluto médio (MAE); raiz do erro quadrático médio (RMSE); viés; índice de concordância de Willmott (d); e o índice de eficiência de Nash-Sutcliffe ( $\left.\mathrm{E}_{\mathrm{NS}}\right)$.

$\mathrm{O}$ valor do índice de concordância de Willmott varia entre 0 e 1 , e valores próximos da unidade indicam concordância, ou seja, melhor desempenho do modelo na estimativa.
Para avaliar o desempenho dos modelos com relação ao índice de eficiência de Nash-Sutcliffe $\left(\mathrm{E}_{\mathrm{NS}}\right)$, foi adotada a classificação seguida por Pereira et al. (2016). De acordo com a classificação: $\mathrm{E}_{\mathrm{NS}}=1$ significa ajuste perfeito dos dados preditos pelo modelo; $\mathrm{E}_{\mathrm{NS}}>0,75$ indica que o modelo é adequado e bom; $0,36<\mathrm{E}_{\mathrm{NS}}<0,75$ indica que o modelo é considerado satisfatório; e $\mathrm{E}_{\mathrm{NS}}<0,36$ indica que o modelo não é satisfatório.

Para quantificar a diferença entre as vazões estimadas pelos modelos conceituais e híbridos propostos neste trabalho, foram calculadas as diferenças $D_{i}$ por meio da Equação

$$
\mathrm{D}_{\mathrm{i}}=\left|\mathrm{O}_{\mathrm{i}}-\mathrm{P}_{\mathrm{i}}\right|
$$

em que: $\mathrm{O}_{\mathrm{i}}$ é a vazão observada no tempo i; e $\mathrm{P}_{\mathrm{i}}$ é a vazão predita no tempo $i$.

Após a obtenção dessas diferenças para os modelos conceituais e híbridos as mesmas foram comparadas utilizando-se o teste t de Student a 5\% de significância. As hipóteses do teste $\mathrm{t}$ foram as seguintes: $\mathrm{H}_{0}$ - não há diferença significativa entre as vazões estimadas pelo modelo conceitual e pelo modelo híbrido; $\mathrm{H}_{1}$ - há diferença significativa entre as vazões estimadas pelo modelo conceitual e pelo modelo modelo híbrido.

\section{Resultados e Discussão}

Nas Tabelas 3 e 4 estão apresentadas as medidas quantitativas do desempenho das RNAs desenvolvidas para estimativa das vazões diárias nas seções de controle Mário de Carvalho (56696000), Rio Piracicaba (56610000) e Carrapato (56640000), assim como as informações referentes aos modelos conceituais chuva-vazão IPH II e SAC-SMA, para fins de comparação.

$\mathrm{Na}$ Tabela 3 são apresentadas apenas as RNAs que tiveram resultados adequados para estimativa das vazões nas três seções de monitoramento de vazão da bacia do rio Piracicaba, sendo possível verificar que as RNAs possuem como dados de entrada as vazões do curso de água defasadas no tempo, a precipitação média da bacia hidrográfica e as vazões estimadas com os modelos conceituais IPH II e SAC-SMA.

Ao associar os modelos IPH II e SAC-SMA com as RNAs verificou-se que os resultados dos modelos conceituais não são suficientes como dados de entrada das redes, tendo sido necessária a utilização das vazões de dias anteriores registradas nas estações fluviométricas, precipitação média e, ou, evapotranspiração de referência.

Dentre os dados de entrada utilizados verificou-se que a vazão de dias anteriores é fundamental como dado de entrada das RNAs por representarem, segundo Oliveira et al. (2013), o efeito do armazenamento.

Com exceção do modelo de RNA que tem como dados de entrada $\mathrm{Q}_{\mathrm{mt}_{-3}} ; \mathrm{Q}_{\mathrm{sac}}$, todos os demais apresentaram valores do índice de Willmott maiores que $0,94 \mathrm{e}$ 
Tabela 3 - Desempenho dos modelos híbridos para estimativa de vazões na bacia do rio Piracicaba-MG, decorrentes da combinação de redes neurais artificias com os modelos conceituais SAC-SMA e IPH II.

\begin{tabular}{|c|c|c|c|c|c|c|c|c|c|c|}
\hline Estação & Modelo & Entrada & Ep & $\mathrm{N} 1$ & $\mathrm{~N} 2$ & MAE & RMSE & Viés & $\mathrm{d}$ & $\mathrm{E}_{\mathrm{NS}}$ \\
\hline \multirow[t]{2}{*}{ Mário de Carvalho } & RNA & $\mathrm{Q}_{\mathrm{Sec}}$ & 100 & 7 & 8 & 15,1 & 33,0 & 0,76 & 0,97 & 0,89 \\
\hline & RNA & $\mathrm{Q}_{\mathrm{t}_{-1}} ; \mathrm{Q}_{\mathrm{iph}}$ & 150 & 7 & 3 & 13,0 & 30,8 & $-0,83$ & 0,97 & 0,90 \\
\hline \multirow[t]{2}{*}{ Rio Piracicaba } & RNA & $\mathrm{P}_{\mathrm{t}} ; \mathrm{E}_{\mathrm{t}} ; \mathrm{Q}_{\mathrm{sac}}$ & 300 & 5 & 7 & 6,4 & 12,0 & 0,18 & 0,95 & 0,81 \\
\hline & RNA & $\mathrm{Q}_{\mathrm{mt}_{-4}} ; \mathrm{Q}_{\mathrm{iph}}$ & 400 & 4 & 5 & 5,0 & 11,5 & 0,40 & 0,95 & 0,83 \\
\hline \multirow[t]{2}{*}{ Carrapato } & RNA & $\mathrm{Q}_{\mathrm{mt}_{-3}} ; \mathrm{Q}_{\mathrm{sac}}$ & 400 & 10 & 2 & 4,8 & 13,9 & 0,21 & 0,89 & 0,66 \\
\hline & RNA & $\mathrm{Q}_{\mathrm{mt}_{-3}} ; \mathrm{Q}_{\mathrm{iph}}$ & 200 & 10 & 3 & 4,2 & 10,8 & 0,46 & 0,94 & 0,80 \\
\hline
\end{tabular}

Q $_{\text {Sac }}$ é a vazão diária estimada com o modelo SAC-SMA $\left(\mathrm{m}^{3} \mathrm{~s}^{-1}\right)$; $\mathrm{Q}_{\mathrm{IPH}}$ é a vazão diária estimada com o modelo IPH II ( $\left.{ }^{3} \mathrm{~s}^{-1}\right)$; $\mathrm{Q}_{\mathrm{t}-\mathrm{n}}$ é a vazão diária defasada em $\mathrm{n}(1,2,3, \ldots, \mathrm{n})$ dias $\left(\mathrm{m}^{3} \mathrm{~s}^{-1}\right) ; \mathrm{Q}_{\mathrm{mt}_{-\mathrm{n}}}$ é a vazão média de $\mathrm{n}(2,3, \ldots, \mathrm{n})$ dias anteriores $\left(\mathrm{m}^{3} \mathrm{~s}^{-1}\right) ; \mathrm{P}_{\mathrm{t}}$ é a precipitação média da bacia no tempo $\mathrm{t}$ $(\mathrm{mm})$ obtida pelo método de Thiessen; $\mathrm{E}_{\mathrm{t}}$ é a evapotranspiração de referência no tempo t (mm) obtida pelo método de Hargreaves e Samani; Ep: número de épocas; $\mathrm{n} 1$ e n2: número de neurônios artificiais na primeira e segunda camada intermediária, respectivamente; $\mathrm{MAE}^{\mathrm{e}} \mathrm{o}$ erro absoluto médio ( $\mathrm{m}^{3} \mathrm{~s}^{-1}$ ); RMSE é a raiz do erro quadrático médio $\left(\mathrm{m}^{3} \mathrm{~s}^{-1}\right)$; d é o índice de concordância de Willmott; ENs é o índice de eficiência de Nash-Sutcliffe.

Tabela 4 - Desempenho dos modelos hidrológicos conceituais SAC-SMA e IPH II para estimativa de vazões na bacia do rio Piracicaba-MG.

\begin{tabular}{lccccccc}
\hline Estação & Modelo & Entrada & MAE & RMSE & Viés & $\mathrm{d}$ & $\mathrm{E}_{\mathrm{NS}}$ \\
\hline Mário de Carvalho & SAC-SMA & $\mathrm{E}_{\mathrm{t}} ; \mathrm{P}_{\mathrm{t}}$ & 16,0 & 35,2 & $-1,0$ & 0,96 & 0,87 \\
& IPH II & $\mathrm{E}_{\mathrm{t}} ; \mathrm{P}_{\mathrm{t}}$ & 17,1 & 33,5 & 0,48 & 0,97 & 0,88 \\
Rio Piracicaba & SAC-SMA & $\mathrm{E}_{\mathrm{t}} ; \mathrm{P}_{\mathrm{t}}$ & 7,7 & 12,8 & $-0,34$ & 0,94 & 0,78 \\
& IPH II & $\mathrm{E}_{\mathrm{t}} ; \mathrm{P}_{\mathrm{t}}$ & 6,0 & 12,0 & $-0,08$ & 0,95 & 0,80 \\
Carrapato & SAC-SMA & $\mathrm{E}_{\mathrm{t}} ; \mathrm{P}_{\mathrm{t}}$ & 6,0 & 12,6 & 0,32 & 0,90 & 0,71 \\
& IPH II & $\mathrm{E}_{\mathrm{t}} ; \mathrm{P}_{\mathrm{t}}$ & 5,8 & 11,6 & $-0,58$ & 0,92 \\
\hline
\end{tabular}

$\mathrm{P}_{\mathrm{t}}$ é a precipitação média da bacia no tempo $\mathrm{t}(\mathrm{mm})$ obtida pelo método de Thiessen; $\mathrm{E}_{\mathrm{t}}$ é a evapotranspiração de referência no tempo $\mathrm{t}$ (mm) obtida pelo método de Hargreaves e Samani; MAE é o erro absoluto médio $\left(\mathrm{m}^{3} \mathrm{~s}^{-1}\right)$; RMSE é a raiz do erro quadrático médio $\left(\mathrm{m}^{3} \mathrm{~s}^{-1}\right)$; $\mathrm{d}$ é o índice de concordância de Willmott; $\mathrm{E}_{\mathrm{NS}}$ é o índice de eficiência de Nash-Sutcliffe.

índices de eficiência de Nash-Sutcliffe maiores que 0,81 . Esses resultados demonstram que os modelos de RNAs (híbridos) propostos são bons para estimativa das vazões diárias na seção de controle Mário de Carvalho (Tabela 3). Em relação ao viés, verifica-se tendência de subestimativa na maior parte das configurações das RNAs.

Ao comparar os dados das Tabelas 3 e 4 verificou-se que a utilização da RNA com a vazão diária estimada com o modelo SAC-SMA $\left(\mathrm{Q}_{\mathrm{sac}}\right)$ para a seção Mário de Carvalho aumentou a exatidão das predições, visto que os valores de MAE e RMSE reduziram aproximadamente $6 \%$ e os valores do índice de concordância (d) e de eficiência de Nash-Sutcliffe $\left(\mathrm{E}_{\mathrm{NS}}\right)$ aumentaram 1 e $2 \%$, respectivamente, comparativamente aos resultados obtidos com o modelo SAC-SMA sem RNAs.

No que se refere à utilização das estimativas do IPH II, obtidas para a seção Mário de Carvalho, como variável de entrada das RNAs, observa-se na Tabela 3 que os melhores resultados foram obtidos com as entradas $\mathrm{Q}_{\mathrm{t}_{-1}} ; \mathrm{Q}_{\mathrm{iph}}$, ou seja, com vazão diária estimada com o modelo IPH II $\left(\mathrm{Q}_{\text {iph }}\right)$ combinada com a vazão registrada no dia anterior. Neste caso, os valores de MAE e RMSE reduziram 24 e $8 \%$, respectivamente, e o valor do índice de eficiência de Nash-Sutcliffe $\left(E_{N S}\right)$ aumentou $2 \%$ comparativamente aos resultados obtidos com o modelo IPH II sem RNAs (Tabelas 3 e 4 ).

A RNA que apresentou o melhor desempenho para a seção Mário de Carvalho foi a que teve como dados de entrada a vazão do curso de água do dia anterior $\left(\mathrm{Q}_{\mathrm{t}_{-1}}\right)$ e a vazão estimada com o modelo IPH II ( $\left.\mathrm{Q}_{\text {iph }}\right)$.

Ao analisar os dados das Tabelas 3 e 4 para a seção de controle rio Piracicaba verificou-se que a utilização das vazões estimadas com os modelos conceituais IPH II e SAC-SMA como variável de entrada das RNAs apresentou resultados satisfatórios. Ao se comparar a vazão média diária estimada com o modelo SAC-SMA $\left(\mathrm{Q}_{\mathrm{sac}}\right) \mathrm{em}$ relação àquelas obtidas com RNA tendo como dados de entrada $\mathrm{Q}_{\mathrm{mt}-2} ; \mathrm{Q}_{\mathrm{sac}}$ (Tabela 3 ) verifica-se que a exatidão das predições aumentou, visto que os valores de MAE e RMSE reduziram aproximadamente 30 e $6 \%$, respectivamente, e os do índice de concordância (d) e de eficiência de Nash-Sutcliffe $\left(E_{N S}\right)$ aumentaram 1 e 3\%, respectivamente (Tabelas 3 e 4 ).

O mesmo ocorreu para o modelo IPH II, pois ao se considerar $\mathrm{Q}_{\mathrm{mt}-4} ; \mathrm{Q}_{\text {iph }}$ como variáveis de entrada da RNA observa-se aumento da exatidão na estimativa das vazões, dado que os valores de MAE e RMSE reduziram aproximadamente 17 e $3 \%$, respectivamente, e o valor do índice 
de eficiência de Nash-Sutcliffe $\left(\mathrm{E}_{\mathrm{NS}}\right)$ aumentou 3\% (Tabelas 3 e 4).

Para a seção de monitoramento Carrapato a utilização do modelo conceitual SAC-SMA associado à RNA apresentou resultado contrário ao esperado, visto que reduziu os valores do coeficiente de Nash-Sutcliffe ( $\left.E_{\mathrm{NS}}\right)$ bem como do índice de concordância de Willmott (d).

Ao comparar a vazão média diária estimada com o modelo SAC-SMA $\left(\mathrm{Q}_{\mathrm{sac}}\right)$ e a RNA que tem como dados de entrada $\mathrm{Q}_{\mathrm{mt}_{-3}} ; \mathrm{Q}_{\mathrm{sac}}$ verifica-se que não ocorreu aumento da exatidão nas predições como nas seções Mário de Carvalho e Rio Piracicaba, visto que o efeito foi apenas a redução do valor do MAE em aproximadamente 19\% (Tabelas 3 e 4).

Ao se considerar $\mathrm{Q}_{\mathrm{mt}_{-3}} ; \mathrm{Q}_{\mathrm{iph}}$, como variáveis de entrada da RNA observa-se aumento da exatidão na estimativa das vazões, dado que os valores de MAE e RMSE reduziram aproximadamente 27 e $7 \%$, respectivamente, e os do índice de concordância (d) e de eficiência de NashSutcliffe $\left(E_{N S}\right)$ aumentaram 4 e $7 \%$, respectivamente, comparativamente aos resultados obtidos com o modelo IPH II sem RNAs (Tabelas 3 e 4). Neste caso, a utilização do modelo IPH II combinado com a RNA resultou em uma estimativa com erros bem menores do que quando utilizado isoladamente.

Ao analisar os valores apresentados na Tabela 4, verifica-se que os modelos híbridos tiveram melhor desempenho para estimar as vazões na Seção Mário de Carvalho, com área de drenagem de $5.304,0 \mathrm{~km}^{2}$, seguida da Estação Rio Piracicaba, com área de $1.164,2 \mathrm{~km}^{2}$; e, por fim, o pior desempenho para determinação das vazões na Seção de Monitoramento Carrapato, com área de drena- gem de $427,5 \mathrm{~km}^{2}$. Desse modo, percebe-se que o desempenho do modelo foi melhor à medida que a área de drenagem aumentou.

A escala de tempo de simulação, a alta variabilidade espacial e temporal dos fenômenos hidrológicos e o rápido deslocamento do escoamento superficial em bacias hidrográficas menores podem ter ocasionado o decréscimo do desempenho dos modelos nas bacias com menor área de drenagem.

Os resultados apresentados na Tabela 5 confirmam que a maior parte dos modelos híbridos propostos, decorrente da combinação dos modelos conceituais com as RNAs, proporciona aumento da acurácia na previsão de vazão.

Percebe-se na Tabela 5 que todos os modelos de RNAs que utilizaram as vazões preditas com o modelo IPH II apresentaram menor diferença média entre os dados observados e estimados. Já a utilização das vazões preditas com o modelo SAC-SMA como dados de entrada das RNA, caracterizando uma conformação híbrida, foi não significativa nas seções de monitoramento Mário de Carvalho e Carrapato (Tabela 5). Em outras palavras, não há evidencia de que as diferenças médias $\overline{\mathrm{D}_{\mathrm{i}}}$ do modelo SACSMA e do modelo híbrido, difiram significativamente entre si, ao nível de 5\% de significância.

Os resultados obtidos na bacia do rio Piracicaba mostraram que o uso de informações obtidas com o modelo IPH II, como dado de entrada de RNAs, proporcionou melhorias nas estimativas das vazões diárias. Esse resultado é corroborado com os obtidos por Nilsson et al. (2006) e Noori e Kalin (2016) que concluíram que a associação de redes neurais com os resultados de um modelo

Tabela 5 - Resultado do teste $t$ aplicado as diferenças (Eq. (3)) entre os valores observados e estimados pelos modelos conceituais e híbridos.

\begin{tabular}{|c|c|c|c|c|c|}
\hline Estação & Modelo & Entrada & $\overline{\mathrm{D}_{\mathrm{i}}}$ & $\mathrm{t}$ & Valor $\mathrm{p}$ \\
\hline \multirow[t]{4}{*}{ Mário de Carvalho } & Híbrido & $\mathrm{Q}_{\mathrm{sac}}$ & 15,1 & $-0,82^{(\mathrm{ns})}$ & 0,41 \\
\hline & SAC-SMA & $E_{t} ; P_{t}$ & 16,0 & & \\
\hline & Híbrido & $\mathrm{Q}_{\mathrm{t}_{-1}} ; \mathrm{Q}_{\mathrm{iph}}$ & 13,0 & $-3,85^{*}$ & $1,18.10^{-4}$ \\
\hline & IPH II & $\mathrm{E}_{\mathrm{t}} ; \mathrm{P}_{\mathrm{t}}$ & 17,1 & & \\
\hline \multirow[t]{4}{*}{ Rio Piracicaba } & Híbrido & $\mathrm{P}_{\mathrm{t}} ; \mathrm{E}_{\mathrm{t}} ; \mathrm{Q}_{\mathrm{sac}}$ & 6,4 & $-3,55^{*}$ & $3,83 \cdot 10^{-4}$ \\
\hline & SAC-SMA & $E_{t} ; P_{t}$ & 7,7 & & \\
\hline & Híbrido & $\mathrm{Q}_{\mathrm{mt}_{-4}} ; \mathrm{Q}_{\mathrm{iph}}$ & 5,0 & $-3,71^{*}$ & $2,05.10^{-4}$ \\
\hline & IPH II & $\mathrm{E}_{\mathrm{t}} ; \mathrm{P}_{\mathrm{t}}$ & 6,0 & & \\
\hline \multirow[t]{4}{*}{ Carrapato } & Híbrido & $\mathrm{Q}_{\mathrm{mt}_{-3}} ; \mathrm{Q}_{\mathrm{sac}}$ & 4,8 & $-1,89^{(\mathrm{ns})}$ & $5,88.10^{-2}$ \\
\hline & SAC-SMA & $E_{t} ; P_{t}$ & 6,0 & & \\
\hline & Híbrido & $\mathrm{Q}_{\mathrm{mt}_{-3}} ; \mathrm{Q}_{\mathrm{iph}}$ & 4,2 & $-3,69^{*}$ & $2,24 \cdot 10^{-4}$ \\
\hline & IPH II & $\mathrm{E}_{\mathrm{t}} ; \mathrm{P}_{\mathrm{t}}$ & 5,8 & & \\
\hline
\end{tabular}

$\mathrm{Q}_{\mathrm{Sac}}$ é a vazão diária estimada com o modelo SAC-SMA $\left(\mathrm{m}^{3} \mathrm{~s}^{-1}\right)$; $\mathrm{Q}_{\mathrm{t}-\mathrm{n}}$ é a vazão diária estimada com o modelo IPH II ( $\left.\mathrm{m}^{3} \mathrm{~s}^{-1}\right)$; $\mathrm{Q}_{\mathrm{t}-\mathrm{n}}$ é a vazão diária defasada em $n(1,2,3, \ldots, n)$ dias $\left(\mathrm{m}^{3} \mathrm{~s}^{-1}\right) ; \mathrm{Q}_{\mathrm{mt}_{-\mathrm{n}}}$ é a vazão média de $\mathrm{n}(2,3, \ldots, \mathrm{n})$ dias anteriores $\left(\mathrm{m}^{3} \mathrm{~s}^{-1}\right) ; \mathrm{P}_{\mathrm{t}}$ é a precipitação média da bacia no tempo $\mathrm{t}$ $(\mathrm{mm})$ obtida pelo método de Thiessen; $\mathrm{E}_{\mathrm{t}}$ é a evapotranspiração de referência no tempo $\mathrm{t}(\mathrm{mm})$ obtida pelo método de Hargreaves e Samani; $\overline{\mathrm{D}_{\mathrm{i}}}$ é a diferença média entre os valores de vazões observados e estimados $\left(\mathrm{m}^{3} \mathrm{~s}^{-1}\right)$; $\mathrm{t}$ é o valor da estatística de teste do teste t para amostras independentes; (ns): não significativo a 5\% de significância; *: significativo a 5\% de significância. 
conceitual provou ser uma excelente alternativa para realizar simulações de escoamento.

A associação do modelo conceitual SAC-SMA com as RNAs não resultou em melhorias expressivas na acurácia das estimativas das vazões diárias da bacia do rio Piracicaba. Na seção de monitoramento Carrapato, por exemplo, a utilização das vazões estimadas com o SACSMA como dado de entrada da RNA chegou a reduzir a exatidão das estimativas das vazões. Esse resultado foi corroborado com os dados do teste $t$ apresentados na Tabela 5 .

Os resultados obtidos neste trabalho indicaram que a qualidade das estimativas do modelo híbrido, formado com a associação de um modelo hidrológico conceitual e RNAs, dependem do modelo conceitual utilizado. No caso da bacia do rio Piracicaba a associação das RNAs com o modelo hidrológico IPH II foi a única que proporcionou melhoria expressiva na estimativa das vazões.

O modelo IPH II é menos complexo em comparação ao SAC-SMA, de fácil manipulação computacional e possui um menor número de parâmetros, o que constitui-se numa grande vantagem nas condições brasileiras. Essas características podem ter contribuído para o melhor desempenho obtido com a conformação híbrida entre o modelo IPH II e as RNAs.

Na Fig. 3 estão apresentados os hidrogramas observados e estimados pelos modelos híbridos que apresentaram os menores erros para as seções de controle Mário de Carvalho, Rio Piracicaba e Carrapato.

Observa-se nessa figura que os modelos apresentaram dificuldade para simular vazões de pico. Apesar desse comportamento, estimaram adequadamente as demais vazões como pode ser observado na Fig. 3 e na análise de resíduos (Tabela 3 ).

\section{Conclusões}

Com base nos resultados obtidos pode-se concluir que a associação das RNAs com o modelo hidrológico IPH II, caracterizando uma conformação híbrida, permitiu melhorar as estimativas das vazões diárias na bacia do rio Piracicaba. Já a associação com o modelo hidrológico SAC-SMA não proporcionou melhoria das estimativas quando comparada aos resultados advindos da aplicação isolada do referido modelo. Verificou-se, portanto, que a qualidade das estimativas do modelo híbrido, formado com a associação de um modelo hidrológico conceitual e RNAs, depende do modelo conceitual utilizado.

Detectou-se, ainda, que os modelos híbridos tiveram melhor desempenho na estimativa das vazões associadas às maiores áreas de drenagem da bacia do rio Piracicaba.

\section{Agradecimentos}

Os autores agradecem à Fundação de Amparo à Pesquisa do Estado de Minas Gerais (FAPEMIG) e ao Conselho Nacional de Desenvolvimento Científico e Tecnológico (CNPq) pelo apoio financeiro para a realização da pesquisa.

\section{Referências}

AICHOURI, I.; HANI, A.; BOUGHERIRA, N.; DJABRI, L.; CHAFFAI, H.; LALLAHEM, S. River flow model using artificial neural networks. Procedia Engineering, v. 74, n. 1, p. 1007-1014, 2015.

ANDREWS, F.T.; CROKE, B.F.W.; JAKEMAN, A.J. An open software environment for hydrological model assessment and development. Environmental Modelling \& Software, v. 26, n. 10, p. 1171-1185, 2011.

ARAÚJO, C.B.C.D.; NETO, S.A.D.; FILHO, F.D.A.S. Streamflow forecasting for the dam Orós/CE from hydrometeorological data using perceptrons. Revista Brasileira de Meteorologia, v. 30, n. 1, p. 37-46, 2015.

ASADI, S.; SHAHRABI, J.; ABBASZADEH, P.; TABANMEHR, S. A new hybrid artificial neural networks for rainfall-runoff process modeling. Neurocomputing, v. 121, n. 1, p. 470-480, 2013.

BORGES JÚNIOR, J.C.F.; ANJOS, R.J.; SILVA, T.J.A.; LIMA, J.R.S.; ANDRADE, C.L.T. Métodos de estimativa da evapotranspiração de referência diária para a microrregião de Garanhuns, PE. Revista Brasileira de Engenharia Agrícola e Ambiental, v. 16, n. 4, p. 380-390, 2012.

BRAVO, J.M.; ALLASIA, D.; COLLISCHONN, W.; TASSI, R.; MELLER, A.; TUCCI, C.E.M. WIN-IPH2: Manual de Usuário. Porto Alegre: Instituto de Pesquisas HidráulicasUFRGS, 2006.

BURNASH, R.J.C. The NWS River Forecast System: catchment modeling. In: SINGH, V.P. (Ed.). Computer models of watershed hydrology. Highlands Ranch, Colorado: Water Resources Publications, 1995. p. 311-366.

DEVI, G.K.; GANASRI, B.P.; DWARAKISH, G.S. A Review on Hydrological Models. Aquatic Procedia, v. 4, n. 1, p. 1001-1007, 2015.

DUAN, Q.; SOROOSHIAN, S.; GUPTA, V.K. Effective and efficient global optimization for conceptual rainfall-runoff models. Water Resources Research, v. 28, n. 4, p. 10151031, 1992.

ELSAFI, S.H. Artificial Neural Networks (ANNs) for flood forecasting at Dongola Station in the River Nile, Sudan. Alexandria Engineering Journal, v. 53, n. 3, p. 655-662, 2014.

GOMES, L.F.C.; MONTENEGRO, S.M.G.L. VALENÇA, M.J. S. Modelo Baseado na Técnica de Redes Neurais para Previsão de Vazões na Bacia do Rio São Francisco. Revista Brasileira de Recursos Hídricos, v. 15, n. 1, p. 5-15, 2010.

GOVINDARAJU, R.S. Artificial neural networks in hydrology I: Preliminary concepts. Journal of Hydrologic Engineering, v. 5, n. 2, p. 115-123, 2000.

MACÊDO, M.N.C.; DIAS, H.C.T.; COELHO, F.M.G.; ARAÚJO, E.A.; SOUZA, M.L.H.; SILVA, E. Precipitação pluvio- 

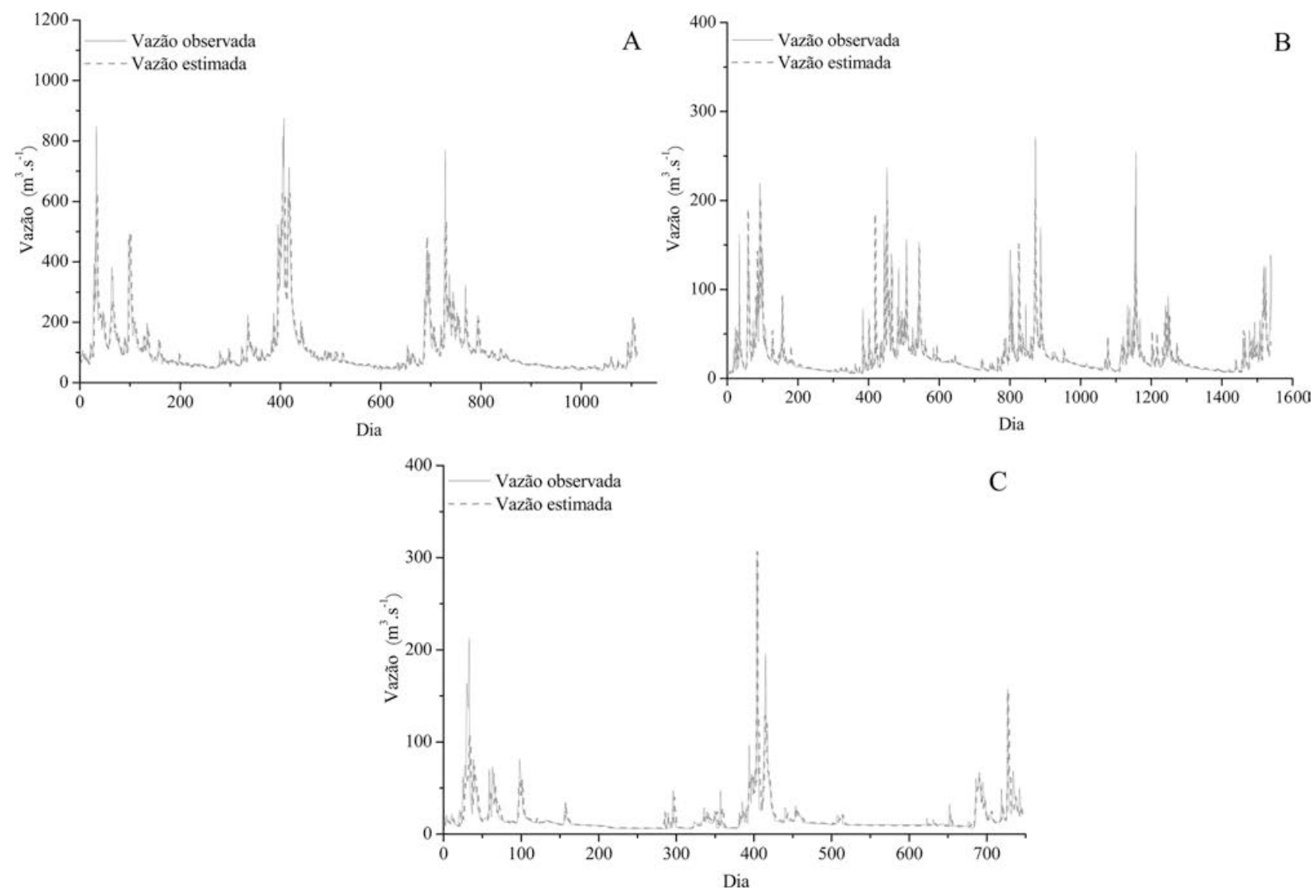

Figura 3 - Hidrograma das vazões observadas e estimadas pelos modelos híbridos tendo como dados de entrada $\mathrm{Q}_{\mathrm{t}_{-1}} ; \mathrm{Q}_{\text {iph }}(\mathrm{A}), \mathrm{Q}_{\mathrm{mt}}$; $\mathrm{Q}_{\mathrm{iph}}(\mathrm{B})$ e $\mathrm{Q}_{\mathrm{mt}-3}$; $\mathrm{Q}_{\text {iph }}$ (C) para as seções de monitoramento Mário de Carvalho, Rio Piracicaba e Carrapato, respectivamente.

métrica e vazão da bacia hidrográfica do Riozinho do Rôla, Amazônia Ocidental. Ambiente \& Água, v. 8, n. 1, p. 206$221,2013$.

MENG, X.; YIN, M.; NING, L.; LIU, D.; XUE, X. A threshold artificial neural network model for improving runoff prediction in a karst watershed. Environmental Earth Sciences, v. 74, n. 6, p. 5039-5048, 2015.

NILSSON, P.; UVO, C.B.; BERNDTSSON, R. Monthly runoff simulation: Comparing and combining conceptual and neural network models. Journal of Hydrology, v. 321, n. 1-4, p. 344-363, 2006.

NOORI, N.; KALIN, L. Coupling SWAT and ANN models for enhanced daily streamflow prediction. Journal of Hydrology, v. 533, n. 1, p. 141-151, 2016.

OLIVEIRA, G.G.; PEDROLLO, O.C.; CASTRO, N.M.R.; BRAVO, J.M. Simulações Hidrológicas com Diferentes Proporções de Área Controlada na Bacia Hidrográfica. Revista Brasileira de Recursos Hídricos, v. 18, n. 3, p. 193-204, 2013.

PECHLIVANIDIS, I.G.; JACKSON, B.M.; MCINTYRE, N.R.; WHEATER, H.S. Catchment Scale Hydrological Modelling: a review of model types, calibration approaches and uncertainty analysis methods in the context of recent developments in technology and applications. Global NEST Journal, v. 13, n. 3, p. 193-214, 2011.
PEREIRA, D.R.; MARTINEZ, M.A.; ALMEIDA, A.Q.; PRUSKI, F.F.; SILVA, D.D.; ZONTA, J.H. Hydrological simulation using SWAT model in headwater basin in southeast Brazil. Engenharia Agrícola, v. 34, n. 4, p. 789-799, 2014.

PEREIRA, D.R.; ULIANA, E.M.; MARTINEZ, M.A.; SILVA, D.D. Desempenho de um Modelo Hidrológico Concentrado e de um Semidistribuído na Predição de Vazões Diárias. Irriga, v. 21, n. 2, p. 409-424, 2016.

SATTARI, M.T.; APAYDIN, H.; OZTURK, F. Flow estimations for the Sohu Stream using artificial neural networks. Environmental Earth Sciences, v. 66, n. 7, p. 2031-2045, 2012.

SETIONO, R. H. Analysis of rainfall-runoff neuron input model with artificial neural network for simulation for availability of discharge at Bah Bolon Watershed. Procedia Engineering, v. 125, n. 1, p. 150-157, 2015.

SILVA, I.N.; SPATTI, D.H.; FLAUZINO, R.A. Redes Neurais Artificiais: Para Engenharia e Ciências Aplicadas. São Paulo: Editora Artliber, 2010. 399 p.

SOUSA, W.S.; SOUSA, F.A.S. Rede neural artificial aplicada à previsão de vazão da Bacia Hidrográfica do Rio Piancó. Revista Brasileira de Engenharia Agrícola e Ambiental, v. 14, n. 2, p. 173-180, 2010.

TUCCI, C.E.M. Modelos Hidrológicos. 2. ed. Porto Alegre: Editora da Universidade/UFRGS e ABRH, 2005. 678 p. 
License information: This is an open-access article distributed under the terms of the Creative Commons Attribution License (type CC-BY), which permits unrestricted use, distribution and reproduction in any medium, provided the original article is properly cited. 